\title{
Efficacy and safety of mepolizumab in Korean patients with severe eosinophilic asthma from the DREAM and MENSA studies
}

\author{
Mi-Kyeong Kim ${ }^{1}$, Hae-Sim Park², Choon-Sik Park ${ }^{3}$, Soung-Jun Min ${ }^{4}$, Frank C. Albers ${ }^{5}$, Steven W. Yancey ${ }^{6}$, \\ Bhabita Mayer ${ }^{7}$, and Namhee Kwon ${ }^{8}$
}

\begin{abstract}
${ }^{1}$ Division of Allergy and Clinical Immunology, Department of Internal Medicine, Chungbuk National University College of Medicine, Cheongju; ${ }^{2}$ Department of Allergy and Clinical Immunology, Ajou University School of Medicine, Suwon; ${ }^{3}$ Department of Pulmonology and Allergy, Soonchunhyang University Bucheon Hospital, Bucheon; ${ }^{4}$ Respiratory Medical, GSK Korea, Seoul, Korea; ${ }^{5}$ Global Respiratory Medical Franchise, GSK, Research Triangle Park, NC; ${ }^{6}$ Respiratory Therapeutic Area, GSK, Research Triangle Park, NC, USA; ${ }^{7}$ Clinical Statistics, GSK, Uxbridge; ${ }^{8}$ Respiratory Medical Franchise, GSK, Brentford, UK
\end{abstract}

Received: June 18, 2019

Revised : August 9, 2019

Accepted: October 15, 2019

\section{Correspondence to}

Hae-Sim Park, M.D.

Department of Allergy and Clinical Immunology, Ajou University School of Medicine, 206 World cup-ro, Yeongtong-gu, Suwon 16499, Korea

Tel: +82-31-219-5150

Fax: +82-31-219-5154

E-mail: hspark@ajou.ac.kr

https://orcid.org/0000-00032614-0303
Background/Aims: The efficacy and safety of mepolizumab in patients with severe eosinophilic asthma has been evaluated in a global clinical trial programme. This post hoc analysis assesses the efficacy and safety of mepolizumab in Korean patients.

Methods: Data from Korean patients in the Phase III, placebo-controlled, randomised DREAM (MEA112997/NCTo1000506) and MENSA (MEA115588/ NCTo1691521) studies were included. Patients $\geq 12$ years old with severe eosinophilic asthma received mepolizumab (DREAM: 75, 250 or $750 \mathrm{mg}$ intravenously [IV]; MENSA: $75 \mathrm{mg}$ IV or $100 \mathrm{mg}$ subcutaneously [SC]), or placebo every 4 weeks for 52 weeks (DREAM) or 32 weeks (MENSA). The primary outcome was the rate of clinically significant asthma exacerbations. Secondary outcomes included forced expiratory volume in 1 second $\left(\mathrm{FEV}_{1}\right)$, Asthma Control Questionnaire (ACQ) and St George's Respiratory Questionnaire (SGRQ) scores (MENSA only). Blood eosinophil counts (BEC) and safety were assessed throughout.

Results: Reductions in the rate of clinically significant asthma exacerbations were observed with the approved (100 mg SC) and bioequivalent ( $75 \mathrm{mg} \mathrm{IV}$ ) doses of mepolizumab in Korean patients who participated in DREAM and MENSA. In MENSA, trends for improvements from baseline at week 32 in pre-bronchodilator $\mathrm{FEV}_{1}$ (75 mg IV group), ACQ-5 and SGRQ scores (in both treatment groups) were seen versus placebo in Korean patients. Incidence of on-treatment adverse events was similar in Korean patients versus non-Korean patients as were observed reductions from baseline in BEC.

Conclusions: Mepolizumab treatment provided clinical benefits for Korean patients with severe eosinophilic asthma; the safety profile is consistent with the overall population.

Keywords: Symptom flare up; Republic of Korea; Therapeutics; Asthma

\section{INTRODUCTION}

Asthma is one of the most prevalent diseases in the Asia-Pacific region, accounting for over $30 \%$ of respira- tory conditions [1]. Severe asthma accounts for approximately $5 \%$ to $10 \%$ of all asthma cases and is defined as asthma that requires treatment with high-dose inhaled corticosteroids (ICS) plus a second controller to main- 
tain control, or asthma that remains uncontrolled despite this treatment [2-4]. The burden of severe asthma in Korea, in terms of use of healthcare facilities and asthma medications, is substantial [5].

Severe asthma is a heterogeneous condition and several clinical phenotypes have been identified, one of which is severe eosinophilic asthma $[2,6,7]$. This phenotype is characterised by elevated eosinophil counts and frequent exacerbations, and patients typically have a poor prognosis $[2,7]$. Currently, several biologic therapies are approved for treating patients with severe eosinophilic asthma [8], including mepolizumab, a humanised monoclonal antibody that targets interleukin-5 to reduce eosinophil levels [9]. In a global Phase III clinical trial programme, mepolizumab was shown to reduce clinically significant exacerbations, improve lung function, asthma control and health-related quality of life (HRQoL) in patients with severe eosinophilic asthma when used as add-on therapy to standard of care [10-12]. These studies have also demonstrated that mepolizumab is well-tolerated with a safety profile similar to placebo [10-12].

Although the majority of monoclonal antibody therapies do not display therapeutic differences across ethnic groups, there is some evidence that therapeutic responses may be influenced by variations in patient characteristics between different ethnic/racial groups, and in a few cases, this may lead to population-specific prescribing recommendations $[13,14]$. This post hoc analysis assessed the efficacy and safety of mepolizumab versus placebo using data from Korean patients enrolled in the Phase IIb/III DREAM (Dose Ranging Efficacy And safety with Mepolizumab in severe asthma) and Phase III MENSA (MEpolizumab as adjunctive therapy iN patients with Severe Asthma) studies to determine whether any therapeutic difference between Korean and non-Korean patients exists.

\section{METHODS}

\section{Study design and treatment}

This was a post hoc subgroup analysis of all studies with Korean patient data available and included data from the Phase III, pivotal, placebo-controlled, randomised, double-blind, parallel-group, multicentre studies, DREAM
(MEA112997/NCTo1000506) and MENSA (MEA115588/ NCTo1691521) [10,11]. Both studies assessed the efficacy and safety of mepolizumab versus placebo in patients with severe eosinophilic asthma. Patients enrolled in DREAM were randomised (1:1:1:1) to receive intravenous (IV) mepolizumab 75, 250, or $750 \mathrm{mg}$, or placebo, plus standard of care, every 4 weeks for 52 weeks. In MENSA, patients were randomised (1:1:1) to receive IV mepolizumab $75 \mathrm{mg}$, mepolizumab $100 \mathrm{mg}$ subcutaneously (SC) or placebo, plus standard of care, every 4 weeks for 32 weeks. The DREAM and MENSA studies were conducted in accordance with the ethical principles of the Declaration of Helsinki, International Conference on Harmonisation Good Clinical Practice Guidelines and applicable country-specific regulatory requirements. All patients provided written informed consent. The study protocols for DREAM and MENSA: NCTo1691521 were approved by local ethics committees.

\section{Patients}

Patients enrolled in DREAM and MENSA were $\geq 12$ years old, had severe eosinophilic asthma, and a history of $\geq 2$ exacerbations requiring systemic corticosteroids in the year prior to enrolment despite regular treatment with high-dose ICS in the 12 months prior to screening and additional controller(s). For DREAM, eosinophilic asthma was indicated as a sputum eosinophil count of $\geq$ $3 \%$, fractional exhaled nitric oxide of $\geq 50$ parts per billion, a blood eosinophil count of $\geq 300$ cells $/ \mu \mathrm{L}$, or a prompt deterioration in asthma control after $\mathrm{a} \leq 25 \%$ reduction in regular maintenance dose of ICS or oral corticosteroids (OCS) within the previous year. For MENSA, eosinophilic asthma was indicated as a blood eosinophil count of $\geq 300$ cells $/ \mu \mathrm{L}$ in the previous year or $\geq 150$ cells $/ \mu \mathrm{L}$ at screening.

\section{Outcomes and assessments}

The primary outcome was the annual rate of clinically significant exacerbations, which was defined as a worsening of asthma, which required the use of systemic corticosteroids for $\geq 3$ days and/or hospitalisation/emergency department visits. Secondary outcomes included blood eosinophil counts, spirometry measurements and Asthma Control Questionnaire (ACQ)-5 (MENSA) or -6 (DREAM) scores, which were obtained every 4 weeks. In MENSA, St George's Respiratory Questionnaire (SGRQ) scores were assessed at randomisation and at the exit 
visit (week 32). SGRQ scores were not available for the DREAM study.

Safety was evaluated by assessment of on-treatment adverse events (AEs), on-treatment serious AEs (SAEs) and immunogenicity. Levels of anti-mepolizumab antibodies were measured at weeks o, 16, 32, and 40 in MENSA, and at weeks 0,16 , and 72 in DREAM.

\section{Sample size and statistical analysis}

This post hoc analysis was based on the Korean patients in the intent-to-treat (ITT) population from DREAM and MENSA, including all randomised Korean patients who received $\geq 1$ dose of study medication. The analysis of exacerbations was performed using a negative binomial model with covariates of treatment group, baseline maintenance OCS therapy (OCS vs. no OCS), number of exacerbations in the previous year (as an ordinal variable), baseline percent predicted forced expiratory volume in 1 second $\left(\mathrm{FEV}_{1}\right)$, and with inclusion of time on treatment as an offset variable.

Changes from baseline in FEV $\mathrm{F}_{1}$, ACQ scores and blood eosinophil counts were analysed using mixed model repeated measures methods. SGRQ scores were analysed by analysis of covariance. Covariates of baseline value, baseline maintenance OCS therapy (OCS vs. no OCS), exacerbations in the year prior to the study (as an ordinal variable), baseline percent predicted $\mathrm{FEV}_{1}$ (except analysis of $\mathrm{FEV}_{1}$ ) and treatment were included in all analysis models, and visit plus interaction terms for visit by baseline and visit by treatment group were included in the mixed model repeated measures analyses. A pre-specified log transformation was applied to blood eosinophil count before analysis.

\section{RESULTS}

\section{Patient population}

In total, the ITT populations included 616 and 576 patients in the DREAM and MENSA studies, respectively. Of these, 24 (3.9\%) and 45 (7.8\%), respectively, were Korean. Across the two studies, three Korean patients were withdrawn, two from the DREAM study and one from the MENSA study. Both patients from DREAM withdrew consent, and the patient from MENSA withdrew because of an $\mathrm{AE}$ (patient was receiving placebo). Patient demographics and clinical characteristics were broadly similar in Korean and non-Korean patients, except there were fewer female patients, patients had a lower mean body mass index (BMI), a higher mean percent predicted $\mathrm{FEV}_{1}$, and lower mean ACQ-5 scores in the Korean group, compared with the non-Korean group (Table 1). Spirometry measurements at baseline, and disease characteristics were also similar between the Korean and non-Korean group across the two studies (Table 1).

\section{Primary outcome}

In DREAM, the annual rate of clinically significant exacerbations in Korean patients was numerically reduced with mepolizumab versus placebo in the $75 \mathrm{mg}$ and $250 \mathrm{mg}$ IV groups, but not in the $750 \mathrm{mg}$ IV group (Fig. 1). Annual rates of exacerbations were 2.00, 1.26 and 3.28 in the mepolizumab $75 \mathrm{mg}, 250 \mathrm{mg}$ and $750 \mathrm{mg} \mathrm{IV}$ groups, respectively, compared with 3.01 in the placebo group. For Korean patients in the MENSA study, reductions in clinically significant exacerbations were seen in both mepolizumab (75 mg IV and $100 \mathrm{mg} \mathrm{SC}$ ) treatment groups versus placebo (Fig. 1). Annual rates of exacerbations were 1.00 and 0.61 in the mepolizumab $75 \mathrm{mg}$ IV and $100 \mathrm{mg}$ SC groups, respectively, compared with 3.16 in the placebo group.

It is of note that in DREAM, five out of six Korean patients experienced $\geq 1$ exacerbation in the placebo group, and although only three out of six patients who were receiving the highest dose of mepolizumab (750 mg IV) experienced $\geq 1$ exacerbation (one of these patients had experienced a total of eight exacerbations). In MEN$\mathrm{SA}$, for Korean patients receiving the approved dose of mepolizumab (100 mg SC) four out of 15 patients experienced $\geq 1$ exacerbation (one of whom experienced a total of seven exacerbations), compared with nine out of 15 patients in the placebo group (Supplementary Table 1).

\section{Secondary outcomes}

For the DREAM study, there were insufficient patient numbers to perform analyses of changes from baseline in $\mathrm{FEV}_{1}$, ACQ-5 scores and blood eosinophil counts. In the MENSA study, a trend for improvements from baseline in pre-bronchodilator $\mathrm{FEV}_{1}$ was seen in Korean patients receiving mepolizumab $75 \mathrm{mg}$ IV compared with placebo, but not with mepolizumab $100 \mathrm{mg}$ SC (Fig. 2). A trend for reductions (improvements) in ACQ-5 scores 
Table 1. Baseline demographics and clinical characteristics (ITT population)

\begin{tabular}{|c|c|c|c|c|}
\hline \multirow[b]{2}{*}{ Characteristic } & \multicolumn{2}{|c|}{$\operatorname{DREAM}(\mathrm{n}=616)$} & \multicolumn{2}{|c|}{$\operatorname{MENSA}(n=576)$} \\
\hline & $\begin{array}{l}\text { Korean } \\
(\mathrm{n}=24)\end{array}$ & $\begin{array}{l}\text { Non-Korean } \\
\quad(n=592)\end{array}$ & $\begin{array}{l}\text { Korean } \\
(\mathrm{n}=45)\end{array}$ & $\begin{array}{l}\text { Non-Korean } \\
\quad(\mathrm{n}=531)\end{array}$ \\
\hline Age, yr & $50.2 \pm 11.72$ & $48.6 \pm 11.27$ & $51.5 \pm 12.94$ & $50.0 \pm 14.40$ \\
\hline Female sex & $13 \pm 54$ & $374 \pm 63$ & $18 \pm 40$ & $311 \pm 59^{\mathrm{a}}$ \\
\hline $\mathrm{BMI}, \mathrm{kg} / \mathrm{m}^{2}$ & $23.7 \pm 2.77$ & $28.7 \pm 5.97^{\mathrm{a}}$ & $24.7 \pm 3.23$ & $28.0 \pm 5.93^{\mathrm{a}}$ \\
\hline \multicolumn{5}{|l|}{ Duration of asthma, yr } \\
\hline$<5$ & $3(13)$ & $76(13)$ & $10(22)$ & $50(9)^{b}$ \\
\hline$\geq 5^{-<15}$ & $9(38)$ & $205(35)$ & $21(47)$ & $171(32)^{b}$ \\
\hline$\geq 15-<25$ & $9(38)$ & $127(21)$ & $11(24)$ & $134(25)^{b}$ \\
\hline$\geq 25$ & $3(13)$ & $184(31)$ & $3(7)$ & $176(33)^{b}$ \\
\hline \multicolumn{5}{|l|}{ Spirometry at baseline } \\
\hline Pre-bronchodilator $\mathrm{FEV}_{1}, \mathrm{~L}$ & $2.1 \pm 0.66$ & $1.9 \pm 0.66$ & $1.8 \pm 0.58$ & $1.8 \pm 0.67$ \\
\hline Pre-bronchodilator percent predicted $\mathrm{FEV}_{1}$ & $77.0 \pm 13.77$ & $59 \cdot 5 \pm 16.04^{a}$ & $67.6 \pm 16.67$ & $60.5 \pm 18.00^{a}$ \\
\hline Pre-bronchodilator FVC, L & $2.8 \pm 0.77$ & $3.0 \pm 0.95$ & $2.8 \pm 0.77$ & $2.9 \pm 0.91$ \\
\hline Pre-bronchodilator $\mathrm{FEV}_{1} / \mathrm{FVC}$ & $0.8 \pm 0.13$ & $0.6 \pm 0.12^{\mathrm{a}}$ & $0.7 \pm 0.14$ & $0.6 \pm 0.13$ \\
\hline Post-bronchodilator $\mathrm{FEV}_{1}, \mathrm{~L}$ & $2.4 \pm 0.77$ & $2.2 \pm 0.75$ & $2.2 \pm 0.66$ & $2.1 \pm 0.71^{\mathrm{c}}$ \\
\hline Post-bronchodilator FVC, L & $3.0 \pm 0.82$ & $3.4 \pm 1.00$ & $3.2 \pm 0.91$ & $3.2 \pm 0.94^{c}$ \\
\hline \multicolumn{5}{|l|}{ Exacerbations in the past 12 mon } \\
\hline 1 & o & $2(<1)^{\mathrm{d}}$ & o & $1(<1)^{\mathrm{e}}$ \\
\hline 2 & $14(58)$ & $270(46)$ & $19(42)$ & $226(43)$ \\
\hline$>2$ & $10(42)$ & $320(54)$ & $26(58)$ & $304(57)$ \\
\hline Receiving maintenance OCS therapy at baseline & $5(21)$ & $183(31)$ & $9(20)$ & $130(24)$ \\
\hline \multirow[t]{2}{*}{ ACQ-5 score } & $\mathrm{n}=23$ & $\mathrm{n}=582$ & $\mathrm{n}=39$ & $\mathrm{n}=520$ \\
\hline & $1.2 \pm 0.90$ & $2.5 \pm 1.12^{\mathrm{a}}$ & $1.6 \pm 1.11$ & $2.3 \pm 1.20^{\mathrm{a}}$ \\
\hline \multirow{2}{*}{$\begin{array}{l}\text { Blood eosinophil count, cells } / \mu \mathrm{L} \text {, geometric } \\
\text { mean } \pm \text { SD logs }\end{array}$} & $\mathrm{n}=24$ & $\mathrm{n}=592$ & $\mathrm{n}=45$ & $\mathrm{n}=524$ \\
\hline & $320.0 \pm 0.81$ & $250.0 \pm 1.04$ & $270.0 \pm 1.02$ & $300.0 \pm 0.99$ \\
\hline \multicolumn{5}{|l|}{ Comorbidities } \\
\hline Nasal polyps & $4(17)$ & $58(10)$ & $9(20)$ & $84(16)$ \\
\hline Atopy $^{\mathrm{f}}$ & $16(67)$ & $295(50)$ & $22(49)$ & $248(47)$ \\
\hline
\end{tabular}

Values are presented as mean $\pm \mathrm{SD}$ or number (\%).

ITT, intent-to-treat; DREAM, Dose Ranging Efficacy And safety with Mepolizumab in severe asthma; MENSA, MEpolizumab as adjunctive therapy iN patients with Severe Asthma; BMI, body mass index; $\mathrm{FEV}_{1}$, forced expiratory volume in 1 second; FVC, forced vital capacity; OCS, oral corticosteroid; ACQ, Asthma Control Questionnaire.

${ }^{a} p<0.05$ within study comparison between Korean and non-Korean patients.

${ }^{b} p<0.05$ for comparison between Korean and non-Korean patients across all categories of duration of asthma in the MENSA study.

'Total number of patients in these groups were $\mathrm{n}=528$.

${ }^{\mathrm{d}}$ One patient in the placebo group and one patient in the mepolizumab $250 \mathrm{mg}$ group had $<2$ exacerbations in the 12 months prior to screening and both were defined as protocol violators.

${ }^{\mathrm{e}}$ One patient in the placebo group had $<2$ exacerbations in the 12 months prior to screening and were defined as protocol violators.

${ }^{\mathrm{f}}$ Atopy status of subjects indicated by a positive skin test for any of four aeroallergens: house dust mite, dog dander, cat dander, Alternaria. 


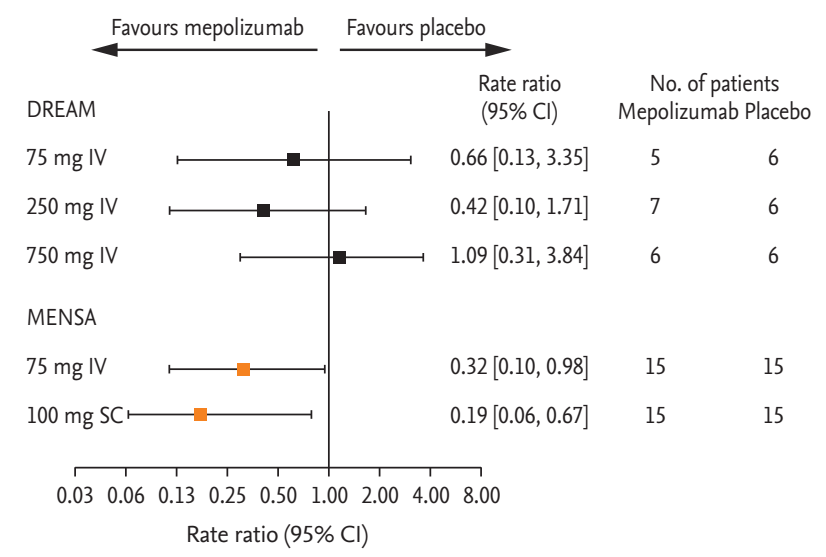

Figure 1. Annual rate of clinically significant exacerbations with mepolizumab versus placebo in Korean patients. DREAM, Dose Ranging Efficacy And safety with Mepolizumab in severe asthma; MENSA, MEpolizumab as adjunctive therapy iN patients with Severe Asthma; CI, confidence interval; IV, intravenous; SC, subcutaneous.

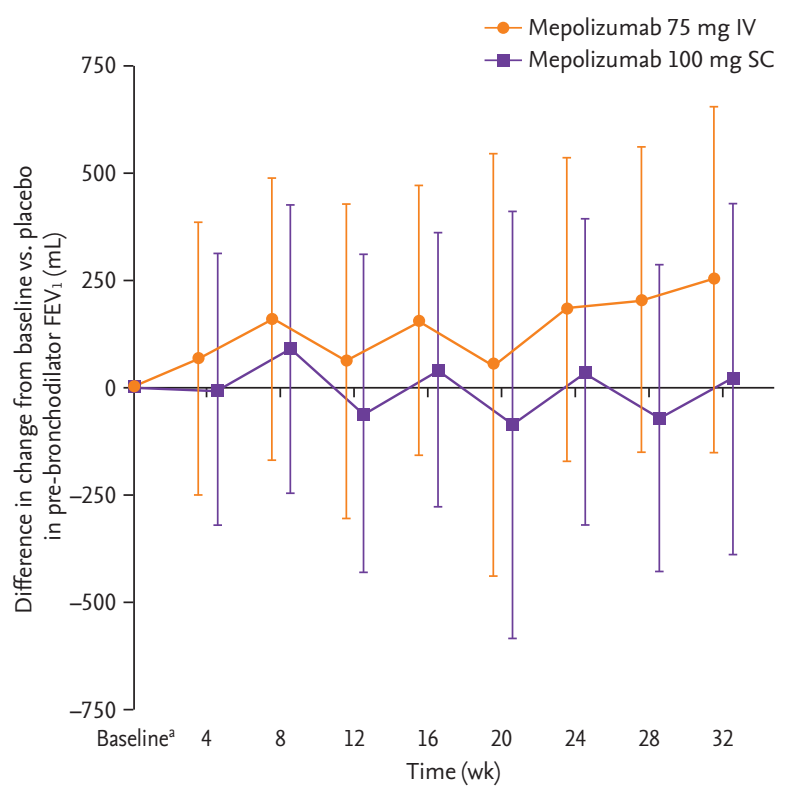

Figure 2. Difference in change from baseline in pre-bronchodilator forced expiratory volume in 1 second $\left(\mathrm{FEV}_{1}\right)$ with mepolizumab versus placebo in Korean patients from the MENSA (MEpolizumab as adjunctive therapy iN patients with Severe Asthma) study. Error bars show 95\% confidence intervals. Patient numbers for each group were: mepolizumab 75 mg intravenous (IV); 15 (all time points); mepolizumab $100 \mathrm{mg}$ subcutaneous (SC); 15 (all time points), and placebo; 15 (baseline, weeks 8 and 16) and 14 (at weeks 24 and 32). ${ }^{a}$ Baseline mean $\pm \mathrm{SD}$ pre-bronchodilator $\mathrm{FEV}_{1} \mathrm{~mL}$ were 1,859 $\pm 623,1,771 \pm 599$, and 1,902 \pm 550 in the $75 \mathrm{mg} \mathrm{IV}, 100 \mathrm{mg}$ SC and placebo groups, respectively.

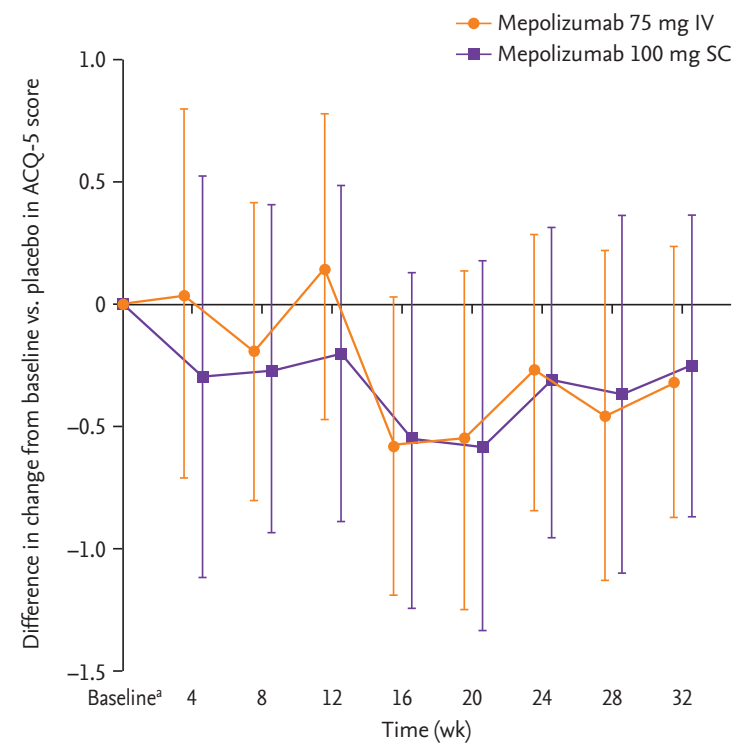

Figure 3. Difference in change from baseline in Asthma Control Questionnaire-5 (ACQ-5) score with mepolizumab versus placebo in Korean patients from the MENSA (MEpolizumab as adjunctive therapy iN patients with Severe Asthma) study. Error bars show 95\% confidence intervals. Patient numbers for each group were: mepolizumab $75 \mathrm{mg}$ intravenous (IV); 12 (baseline, weeks 8, 16 and 24), 11 (week 32); mepolizumab $100 \mathrm{mg}$ subcutaneous (SC); 13 (baseline, weeks 8, 24 and 32), 12 (week 16), and placebo; 14 (baseline, weeks 8 and 16) and 13 (at weeks 24 and 32). ${ }^{2}$ Baseline mean \pm SD ACQ-5 scores were $1.6 \pm 1.04,1.1 \pm 0.79$, and $2.2 \pm 1.2$ for the $75 \mathrm{mg} \mathrm{IV,} 100 \mathrm{mg} \mathrm{SC}$ and placebo groups, respectively.

in Korean patients was also seen with mepolizumab 100 mg SC versus placebo at week 4 and with both doses (100 $\mathrm{mg} \mathrm{SC}$ and $75 \mathrm{mg}$ IV) at week 8, and was maintained until week 32 (except for week 12 in the $75 \mathrm{mg}$ IV group)(Fig. 3). In addition, there were numerical reductions (improvements) from baseline in SGRQ scores seen at week 32 in both treatment groups versus placebo (adjusted change from baseline [ $95 \%$ confidence interval, CI] in $75 \mathrm{mg}$ IV $[\mathrm{n}=15]:-3.0$ [95\% CI, -13.8 to 7.8$] ; 100 \mathrm{mg}$ SC $[\mathrm{n}=15]:-0.2$ [95\% CI, -11.8 to 11.4]) (data not shown). Reductions from baseline in blood eosinophil counts for Korean patients were seen with both mepolizumab doses ( $75 \mathrm{mg}$ IV and $100 \mathrm{mg} \mathrm{SC}$ ), versus placebo at week 4 , and these reductions were maintained until week 32 (Fig. 4).

\section{Safety}

The most frequently reported on-treatment AEs in Korean patients across all treatment groups were upper 


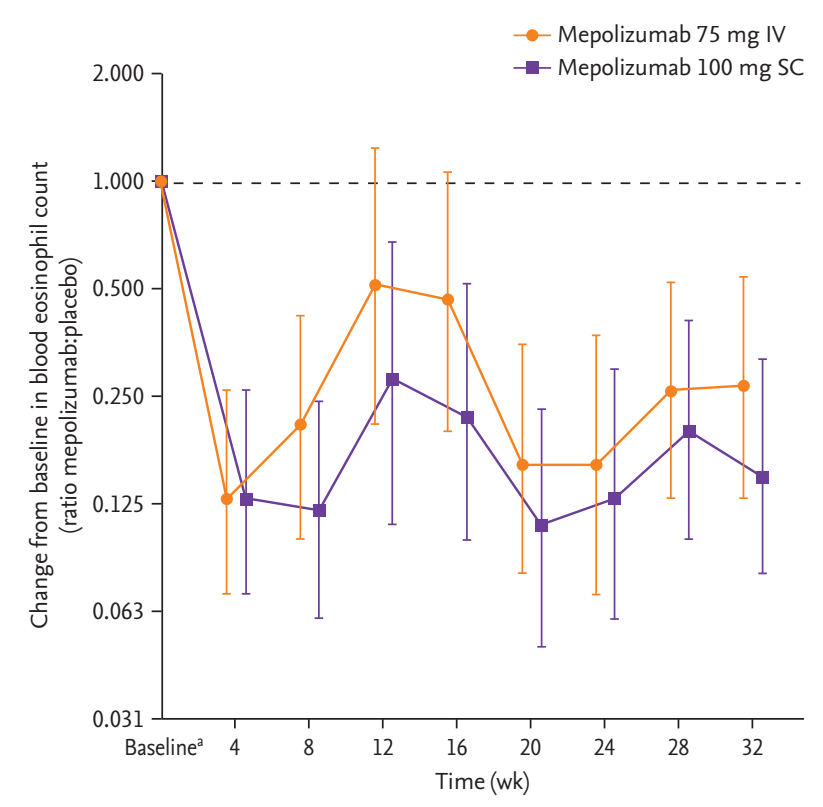

Figure 4. Ratio of change from baseline in blood eosinophil count with mepolizumab versus placebo in Korean patients from the MENSA (MEpolizumab as adjunctive therapy iN patients with Severe Asthma) study. Error bars show 95\% confidence intervals. Patient numbers for each group were: mepolizumab $75 \mathrm{mg}$ intravenous (IV); 15 (baseline, weeks 16, 24 and 32) and 13 (week 8); mepolizumab 100 mg subcutaneous (SC); 15 (all time points), and placebo; 15 (baseline) and 14 (weeks 8, 16, 24 and 32 ). ${ }^{\text {a }}$ Baseline geometric mean \pm SD logs blood eosinophil counts, in cells $/ \mu \mathrm{L}$, were $300 \pm 0.82,290 \pm$ 1.05 , and $240 \pm 1.23$ in the $75 \mathrm{mg} \mathrm{IV}, 100 \mathrm{mg}$ SC and placebo groups, respectively.

respiratory tract infection (DREAM and MENSA), nasopharyngitis (MENSA) and sinusitis (DREAM [excluding the $75 \mathrm{mg}$ IV group], and MENSA) (Table 2). The incidence of reported on-treatment SAEs in Korean patients was low across both studies, with four patients reporting an SAE in MENSA placebo, two in MENSA $75 \mathrm{mg}$, and one each in DREAM $250 \mathrm{mg}, 750 \mathrm{mg}$ and MENSA $100 \mathrm{mg}$ groups (Table 2). One fatality across the two studies was reported, which was a Korean patient receiving placebo in the MENSA study. Overall, no anti-drug antibodies were detected in Korean patients at week o or at any time post-baseline. For both the DREAM and MENSA studies, no neutralising antibodies were detected in Korean patients during the treatment period.

\section{DISCUSSION}

This post hoc analysis of the pivotal Phase III DREAM and MENSA studies assessed, for the first time, the safety and efficacy of mepolizumab in Korean patients with severe eosinophilic asthma. We found that in Korean patients mepolizumab (100 $\mathrm{mg}$ SC and $75 \mathrm{mg} \mathrm{IV}$ ) was associated with a reduction in the rate of clinically significant exacerbations compared with placebo; improvements in lung function, asthma control, and HRQoL were also seen, as well as reductions in blood eosinophil counts. These findings demonstrate that mepolizumab is a beneficial treatment for Korean patients with severe eosinophilic asthma.

Our results are broadly consistent with those seen in the overall ITT population in DREAM and MENSA as well as another Phase III clinical trial, where reductions in clinically significant exacerbations, trends for improvements in lung function and HRQoL were observed along with reductions in blood eosinophil counts [1012]. It is important to note that in our analysis, Korean patients treated with the highest dose of mepolizumab (750 mg IV) did not show a significant reduction in exacerbations compared with placebo, which is in contrast to results seen in the overall ITT population in DREAM [11]. One patient in this treatment group may have unduly influenced these results having experienced a total of eight exacerbations during the study; however, the sample size was low and thus this result should be viewed with caution.

In Korean patients from the DREAM and MENSA studies, the majority of patients reported $\geq 1$ on-treatment $\mathrm{AE}$ across the different treatment groups (with frequencies of any AEs ranging from $80 \%$ to $100 \%$ ). This is consistent with those reporting such events in the overall ITT population of MENSA ( $78 \%$ to $84 \%$ in the mepolizumab groups; $83 \%$ in the placebo group) and DREAM ( $78 \%$ to $82 \%$ in the mepolizumab groups; $77 \%$ in the placebo group) $[10,15]$. The most commonly-reported AEs in the overall ITT population were broadly similar to those in Korean patients, although the incidence of headaches appeared to be less common in Korean patients. In addition, the incidence of SAEs was broadly similar to that reported in the overall ITT population in the DREAM and MENSA studies $[10,11]$ and there were no fatalities considered related to treatment. 
Table 2. Summary of AEs and SAEs (ITT population)

\begin{tabular}{|c|c|c|c|c|c|c|c|}
\hline \multirow[b]{2}{*}{ Characteristic } & \multicolumn{4}{|c|}{ DREAM $(n=24)$} & \multicolumn{3}{|c|}{$\operatorname{MENSA}(n=45)$} \\
\hline & $\begin{array}{c}\text { Placebo } \\
(n=6)\end{array}$ & $\begin{array}{c}75 \text { mg IV } \\
(\mathrm{n}=5)\end{array}$ & $\begin{array}{c}250 \mathrm{mg} \text { IV } \\
(\mathrm{n}=7)\end{array}$ & $\begin{array}{c}750 \mathrm{mg} \text { IV } \\
(\mathrm{n}=6)\end{array}$ & $\begin{array}{c}\text { Placebo } \\
(\mathrm{n}=15)\end{array}$ & $\begin{array}{c}75 \text { mg IV } \\
(\mathrm{n}=15)\end{array}$ & $\begin{array}{c}100 \mathrm{mg} \mathrm{SC} \\
(\mathrm{n}=15)\end{array}$ \\
\hline \multicolumn{8}{|l|}{ On-treatment AEs ${ }^{\mathrm{a}}$} \\
\hline Any & $6(100)$ & $4(80)$ & $7(100)$ & $6(100)$ & $15(100)$ & $14(93)$ & $14(93)$ \\
\hline URTI & $3(50)$ & $4(80)$ & $4(57)$ & $6(100)$ & $5(33)$ & $3(20)$ & $4(27)$ \\
\hline Sinusitis & $2(33)$ & o & $2(29)$ & $2(33)$ & $2(13)$ & $2(13)$ & $2(13)$ \\
\hline Nasopharyngitis & 0 & $\mathrm{O}$ & $\mathrm{O}$ & 0 & $6(40)$ & $5(33)$ & $4(27)$ \\
\hline Tinea pedis & $2(33)$ & 0 & 0 & 0 & 0 & 0 & 0 \\
\hline Face oedema & o & 0 & o & $2(33)$ & o & 0 & o \\
\hline Fatigue & 0 & 0 & $2(29)$ & 0 & 0 & o & 0 \\
\hline Asthma & o & o & $2(29)$ & 0 & $2(13)$ & $1(7)$ & $\mathrm{O}$ \\
\hline Rhinorrhoea & 0 & 0 & $\mathrm{O}$ & $2(33)$ & 0 & o & 0 \\
\hline Influenza-like illness & o & 0 & 0 & 0 & o & $3(20)$ & o \\
\hline Hypertension & 0 & 0 & 0 & 0 & 0 & $2(13)$ & $1(7)$ \\
\hline \multicolumn{8}{|l|}{ On-treatment SAEs ${ }^{\mathrm{b}}$} \\
\hline Any & 0 & 0 & $1(14)$ & $1(17)$ & $4(27)$ & $2(13)$ & $1(7)$ \\
\hline Tonsillitis & 0 & 0 & $\mathrm{O}$ & $1(17)$ & $\mathrm{O}$ & 0 & o \\
\hline Urinary retention & 0 & 0 & $1(14)$ & 0 & o & 0 & o \\
\hline Contusion & $\mathrm{O}$ & $\mathrm{o}$ & $\mathrm{O}$ & o & $1(7)$ & $\mathrm{O}$ & $\mathrm{o}$ \\
\hline Road traffic accident & 0 & 0 & 0 & 0 & $1(7)$ & o & 0 \\
\hline Asthma & o & o & o & o & $1(7)$ & $1(7)$ & o \\
\hline Herpes zoster & o & 0 & 0 & o & o & o & $1(7)$ \\
\hline Sciatica & o & 0 & 0 & 0 & o & $1(7)$ & o \\
\hline Calculus ureteric & 0 & 0 & 0 & 0 & $1(7)$ & 0 & o \\
\hline Calculus urethral & o & o & o & 0 & $1(7)$ & o & o \\
\hline Nephrolithiasis & 0 & 0 & 0 & 0 & $1(7)$ & o & 0 \\
\hline
\end{tabular}

Values are presented as number (\%).

AE, adverse event; SAE, serious adverse event; ITT, intent-to-treat; DREAM, Dose Ranging Efficacy And safety with Mepolizumab in severe asthma; MENSA, MEpolizumab as adjunctive therapy iN patients with Severe Asthma; IV, intravenous; SC, subcutaneous; URTI, upper respiratory tract infection.

${ }^{a} A$ Es occurring in $\geq 2$ patients in a treatment group.

${ }^{\mathrm{b}} \mathrm{SAEs}$ occurring in $\geq 1$ patient in a treatment group.

During the treatment period, no anti-drug antibodies were detected in Korean patients, which is in line with the low immunogenic response observed in the mepolizumab clinical trial programme. Taken together, these results demonstrate that mepolizumab is well-tolerated in Korean patients, with no additional safety concerns identified.

Racial differences have been reported to influence treatment responses in patients with asthma. For example, in an analysis of 1,200 patients with asthma from
10 trials, African Americans were shown to have an increased rate of treatment failures (defined as asthma exacerbations, worsening of lung function, increased use of asthma medication or physician-determined) compared with Caucasians when treated with long-acting b-agonists [16]. However, it is not known whether these differences are a result of genetic, environmental or socioeconomic factors or inherent pathophysiologic or pharmacogenomic differences [16]. Obesity has also been found to be associated with increased asthma se- 
verity and poor asthma control [17]. However, weight and body mass index may play less of a role in Asian populations as they tend to be lower than in other populations [18]. To date, there is limited information on the efficacy and safety of mepolizumab in specific population cohorts. However, a prospective, open-label study of Japanese patients $(\mathrm{n}=32)$, and a post hoc analysis of Japanese patients from the MENSA study $(n=50)$ have demonstrated that mepolizumab treatment (100 mg SC and $75 \mathrm{mg} \mathrm{IV}$ ) is associated with reductions in the rate of clinically significant exacerbations and improvements in lung function in patients with severe eosinophilic asthma $[19,20]$, similar findings to those reported here for Korean patients. Together, these studies do not suggest the presence of clinically relevant inter-ethnic differences in response to mepolizumab treatment.

In this post hoc analysis, the main limitation was the small number of Korean patients in each treatment group, and for the DREAM study this meant that there were insufficient patient numbers to perform formal analyses relating to change from baseline in pre-bronchodilator $\mathrm{FEV}_{1}$, ACQ-5 and blood eosinophil counts with mepolizumab versus placebo. These small sample sizes may reduce the generalisability of the results observed to the wider Korean population. Nonetheless, our findings provide valuable insights into the use of mepolizumab in Korean patients.

In conclusion, this post hoc subgroup analysis of the DREAM and MENSA studies demonstrates a clinically relevant reduction in the rate of asthma exacerbations with mepolizumab compared with placebo in Korean patients with severe eosinophilic asthma. Trends for improvements in lung function, asthma control and HRQoL were also observed, and the safety profile in Korean patients was consistent with that seen in the overall study population. Taken together, these results indicate that treatment with mepolizumab is of clinical benefit in Korean patients with severe eosinophilic asthma.

\section{KEY MESSAGE}

1. Post hoc analysis of data from the Phase III studies, DREAM (Dose Ranging Efficacy And safety with Mepolizumab in severe asthma) and MENSA (MEpolizumab as adjunctive ther- apy iN patients with Severe Asthma), evaluated the efficacy and safety of mepolizumab in Korean patients with severe eosinophilic asthma.

2. Here, we demonstrate that mepolizumab reduces the rate of clinically significant asthma exacerbations, improves lung function, and is well-tolerated in this patient population.

\section{Conflict of interest}

Namhee Kwon, Soung-Jun Min, Frank C. Albers, Steven W. Yancey, and Bhabita Maye are employees of GSK and hold stocks/shares. Hae-Sim Park, Mi-Kyeong Kim, and Choon-Sik Park have no financial or other issues that might lead to conflict of interest.

\section{Acknowledgments}

This post hoc analysis and the parent studies (DREAM, MEA112997/NCT01000506 and MENSA, MEA115588/ NCTo1691521) were funded by GlaxoSmithKline (GSK). The study nurse and institution service funded by the Korean government (KHIDI [HI16Co992]) also played a role in the conduct of the DREAM and MENSA studies.

Editorial support (in the form of writing assistance, including development of the initial draft, assembling tables and figures, collating authors comments, grammatical editing and referencing) was provided by Sarah Farrar, Ph.D., from Fishawack Indicia Ltd., and was funded by GSK.

\section{REFERENCES}

1. Yoo KH, Ahn HR, Park JK, et al. Burden of respiratory disease in Korea: an observational study on allergic rhinitis, asthma, COPD, and rhinosinusitis. Allergy Asthma Immunol Res 2016;8:527-534.

2. Chung KF, Wenzel SE, Brozek JL, et al. International ERS/ ATS guidelines on definition, evaluation and treatment of severe asthma. Eur Respir J 2014;43:343-373.

3. O'Byrne PM, Naji N, Gauvreau GM. Severe asthma: future treatments. Clin Exp Allergy 2012;42:706-711.

4. Fajt ML, Wenzel SE. Development of new therapies for severe asthma. Allergy Asthma Immunol Res 2017;9:3-14.

5. Kim MH, Kim SH, Park SY, et al. Characteristics of adult severe refractory asthma in Korea analyzed from the 
severe asthma registry. Allergy Asthma Immunol Res 2019;11:43-54.

6. Wenzel SE. Asthma: defining of the persistent adult phenotypes. Lancet 2006;368:804-813.

7. ten Brinke A, Zwinderman AH, Sterk PJ, Rabe KF, Bel EH. "Refractory" eosinophilic airway inflammation in severe asthma: effect of parenteral corticosteroids. Am J Respir Crit Care Med 2004;170:601-605.

8. Yancey SW, Keene ON, Albers FC, et al. Biomarkers for severe eosinophilic asthma. J Allergy Clin Immunol 2017;140:1509-1518.

9. Nucala. Prescribing information [Internet]. Research Triangle Park (NC): GlaxoSmithKline, c2019 [cited $2020 \mathrm{Feb}$ 21]. Available from: https://www.gsksource.com/pharma/ content/dam/GlaxoSmithKline/US/en/Prescribing_Information/Nucala/pdf/NUCALA-PI-PIL.PDF.

10. Ortega HG, Liu MC, Pavord ID, et al. Mepolizumab treatment in patients with severe eosinophilic asthma. N Engl J Med 2014;371:1198-1207.

11. Pavord ID, Korn S, Howarth P, et al. Mepolizumab for severe eosinophilic asthma (DREAM): a multicentre, double-blind, placebo-controlled trial. Lancet 2012;380:651659 .

12. Chupp GL, Bradford ES, Albers FC, et al. Efficacy of mepolizumab add-on therapy on health-related quality of life and markers of asthma control in severe eosinophilic asthma (MUSCA): a randomised, double-blind, placebo-controlled, parallel-group, multicentre, phase $3 \mathrm{~b}$ trial.
Lancet Respir Med 2017;5:390-400.

13. Chiba K, Yoshitsugu H, Kyosaka Y, et al. A comprehensive review of the pharmacokinetics of approved therapeutic monoclonal antibodies in Japan: are Japanese phase I studies still needed? J Clin Pharmacol 2014;54:483-494.

14. Ramamoorthy A, Pacanowski MA, Bull J, Zhang L. Racial/ ethnic differences in drug disposition and response: review of recently approved drugs. Clin Pharmacol Ther 2015;97:263-273.

15. GSK. Clinical study report 2014 [Internet]. Research Triangle Park (NC): GlaxoSmithKline, 2014 [cited 2020 Feb 21]. Available from: https://www.gsk.com.

16. Wechsler ME, Castro M, Lehman E, et al. Impact of race on asthma treatment failures in the asthma clinical research network. Am J Respir Crit Care Med 2011;184:1247-1253.

17. Baffi CW, Winnica DE, Holguin F. Asthma and obesity: mechanisms and clinical implications. Asthma Res Pract 2015;1:1.

18. WHO Expert Consultation. Appropriate body-mass index for Asian populations and its implications for policy and intervention strategies. Lancet 2004;363:157-163.

19. Shimoda T, Odajima H, Okamasa A, et al. Efficacy and safety of mepolizumab in Japanese patients with severe eosinophilic asthma. Allergol Int 2017;66:445-451.

20. Kurosawa M, Sutoh E. Prospective open-label study of 48-week subcutaneous administration of mepolizumab in Japanese patients with severe eosinophilic asthma. J Investig Allergol Clin Immunol 2019;29:40-45. 
Supplementary Table 1. Summary of frequency of clinically significant exacerbations in Korean patients from the DREAM and MENSA studies ${ }^{\mathrm{a}}$

\begin{tabular}{|c|c|c|c|c|c|c|c|}
\hline \multirow[b]{2}{*}{$\begin{array}{l}\text { No. of } \\
\text { exacerbations }\end{array}$} & \multicolumn{4}{|c|}{ DREAM } & \multicolumn{3}{|c|}{ MENSA } \\
\hline & $\begin{array}{l}\text { Placebo } \\
(n=6)\end{array}$ & $\begin{array}{c}\text { Mepolizumab } \\
75 \mathrm{mg} \text { IV } \\
(\mathrm{n}=5)\end{array}$ & $\begin{array}{c}\text { Mepolizumab } \\
250 \text { mg IV } \\
(\mathrm{n}=7)\end{array}$ & $\begin{array}{c}\text { Mepolizumab } \\
750 \text { mg IV } \\
(\mathrm{n}=6)\end{array}$ & $\begin{array}{c}\text { Placebo } \\
(\mathrm{n}=15)\end{array}$ & $\begin{array}{c}\text { Mepolizumab } \\
75 \text { mg IV } \\
(\mathrm{n}=15)\end{array}$ & $\begin{array}{c}\text { Mepolizumab } \\
100 \mathrm{mg} \mathrm{SC} \\
(\mathrm{n}=15)\end{array}$ \\
\hline O & $1(17)$ & $2(40)$ & $3(43)$ & $3(50)$ & $6(40)$ & $8(53)$ & $11(73)$ \\
\hline 1 & $1(17)$ & $1(20)$ & $1(14)$ & $1(17)$ & $3(20)$ & $5(33)$ & $3(20)$ \\
\hline 2 & $2(33)$ & $1(20)$ & $2(29)$ & $\mathrm{o}$ & $1(7)$ & $1(7)$ & o \\
\hline 3 & $1(17)$ & o & $1(14)$ & 0 & $1(7)$ & o & o \\
\hline 4 & o & $\mathrm{O}$ & o & $1(17)$ & $2(13)$ & $\mathrm{o}$ & o \\
\hline 5 & 0 & 0 & 0 & 0 & 0 & o & 0 \\
\hline 6 & $1(17)$ & $1(20)$ & o & o & $2(13)$ & $1(7)$ & o \\
\hline 7 & 0 & o & o & o & o & 0 & $1(7)$ \\
\hline 8 & o & 0 & o & $1(17)$ & o & o & o \\
\hline 9 & 0 & 0 & 0 & 0 & 0 & 0 & 0 \\
\hline$\geq 10$ & o & 0 & o & 0 & 0 & 0 & 0 \\
\hline
\end{tabular}

Values are presented as number (\%).

DREAM, Dose Ranging Efficacy And safety with Mepolizumab in severe asthma; MENSA, MEpolizumab as adjunctive therapy iN patients with Severe Asthma; IV, intravenous; SC, subcutaneous.

aTotal treatment period was 52 weeks (DREAM) and 32 weeks (MENSA). 